EKONOMI BISNIS DAN KEWIRAUSAHAAN

Vol. VIII, No. 1, Januari 2019

\title{
Struktur Corporate Governance, Reputasi Underwriter Dan Initial Public Offering (Ipo) Underpricing Di Indonesia
}

\author{
Purwanto Purwanto'), Bambang Nur Cahyaningrum²) \\ 1) Fakultas Ekonomi Universitas Veteran Bangun Nusantara Sukoharjo \\ J1. Let. Jend. S. Humardani No. 1, Sukoharjo, \\ Telp. (0271) 593156 ext. 143, Fax. (0271) 591065 \\ anto.c412@gmail.com
}

\begin{abstract}
ABSTRAK
Penelitian ini bertujuan untuk mengkaji apakah struktur corporate governance perusahaan dan reputasi underwriter mempengaruhi IPO underpricing perusahaan yang go public dengan menggunakan periode tahun 2010-2016. Penelitian ini menitikberatkan pada pengaruh reputasi underwriter dan struktur corporate governance yaitu komposisi dewan komisaris independen, komite audit dan dewan direksi.

Penelitian ini merupakan penelitian ekspost facto dengan menggunakan dimensi waktu cross sectional study. Populasi yang digunakan dalam penelitian ini adalah seluruh perusahaan yang melakukan Initial Public Offering (IPO) di Bursa Efek Indonesia (BEI) selama periode 2010-2016. Jumlah sampel dalam penelitian ini adalah 117 perusahaan. Teknik pengambilan sampel yang digunakan adalah purposive sampling. Hasil penelitian ini menunjukkan bahwa reputasi underwriter dan dewan direksi berpengaruh signifikan terhadap IPO Underpricing di Indonesia.
\end{abstract}

Keywords : IPO Underpricing, reputasi underwriter dan struktur corporate governance 


\section{PENDAHULUAN}

Penelitian ini bertujuan untuk mengkaji apakah struktur corporate governance perusahaan dan reputasi underwriter mempengaruhi IPO underpricing perusahaan yang go public dengan menggunakan periode tahun 2010-2016. Penelitian ini menitikberatkan pada pengaruh struktur corporate governance yaitu jumlah anggota dewan komisaris, komposisi dewan komisaris independen, komite audit, kepemilikan institusional, kepemilikan manajerial dan dewan direksi.

Manfaat kegiatan Initial Public Offering (IPO) bagi sebuah perusahaan adalah mendapatkan tambahan modal yang berguna untuk memperluas usahanya. Saat ini, semakin banyak perusahaan yang memutuskan untuk melakukan Initial Public Offering (IPO. Fenomena ini dapat mengakibatkan semakin besar pula persaingan antar perusahaan tersebut untuk mendapatkan investor yang akan membeli saham perdana mereka. Persaingan tersebut nantinya akan berpengaruh terhadap harga saham perdana. Penentuan harga jual saham perdana merupakan kesepakatan antara emiten dan underwriter. Hal ini terjadi karena belum ada ukuran yang dapat dijadikan sebagai dasar pertimbangan dalam menentukan harga saham. Permasalahan yang sering kali muncul saat kegiatan IPO adalah terjadinya underpricing. Underpricing adalah kondisi dimana saham perdana yang ditawarkan harganya jauh lebih rendah dibandingkan saat diperdagangkan di pasar sekunder.

Asimetris informasi antara investor dan emiten sering kali menjadi penyebab terjadinya underpricing. Menurut Johnston dan Madura (2009), semakin besar tingkat asimetris informasi dari perusahaan yang melakukan IPO maka semakin besar pula tingkat underpricing yang dialami. Menurut Indriani dan Marlia (2014) tingkat underpricing untuk perusahaan yang melakukan IPO di Indonesia diatas 77\%. Untuk meminimalkan terjadinya underpricing saat penjualan saham perdana, perusahaan (emiten) menerbitkan prospektus perusahaan. Prospektus ini diharapkan menjadi sumber informasi yang dapat menurunkan asimetris informasi antar emiten dan investor.

Perusahaan yang akan go public membutuhkan pengelolaan corporate governance yang baik agar dapat dipercaya investor. Menurut Nuswandari (2009), Corporate governance adalah sebuah konsep yang menekankan pentingnya hak pemegang saham untuk memperoleh informasi yang akurat, benar dan tepat waktu. Selain itu, perusahaan wajib untuk mengungkapkan semua informasi yang berkaitan dengan kinerja perusahaan secara akurat, tepat waktu dan transparan.

Corporate governance yang merupakan konsep yang didasarkan pada agency theory (teori keagenan), diharapkan bisa berfungsi sebagai alat untuk memberikan keyakinan kepada para investor bahwa mereka akan menerima imbal hasil atas dana yang telah mereka investasikan ke perusahaan. Herawaty (2008) menyatakan bahwa corporate governance merupakan suatu sistem pengaturan dan pengendalian perusahaan, yang diharapkan dapat meningkatkan nilai perusahaan kepada para pemegang saham. Sedangkan Underwriter (penjamin emisi), sebagai pihak yang membantu perusahaan untuk go public, akan mendapatkan manfaat dari proses go public 
EKONOMI BISNIS DAN KEWIRAUSAHAAN

Vol. VIII, No. 1, Januari 2019

ini. Semakin sering perusahaan penjamin emisi menangani kegiatan IPO maka akan semakin baik pula reputasinya.

\section{PENGEMBANGAN HIPOTESIS}

1. Ukuran dewan komisaris

Jumlah anggota dalam dewan komisaris memiliki peran penting dalam meningkatkan keefektifan di dalam suatu board (Rahmida, 2012). Jumlah anggota dewan komisaris mempunyai peranan penting dalam mengurangi agency problem antara manajer dan pemegang saham, selain itu jumlah anggota dewan komisaris akan sangat berpengaruh terhadap pelaksanaan kegiatan operasional perusahaan. Hidayat dan Kusumawati (2014) menyatakan bahwa ukuran dewan komisaris terbukti berpengaruh negatif terhadap underpricing. Oleh karena itu dikembangkan hipotesis yang pertama, yaitu :

\section{$H_{1}$ : Ukuran dewan komisaris berpengaruh negatif terhadap IPO underpricing}

2. Komposisi Dewan Komisaris Independen

Lin dan Chuang (2011) menyatakan bahwa dewan komisaris independen memiliki pengaruh signifikan negatif terhadap tingkat underpricing. Noviawan dan Septiani (2013) menyatakan bahwa dengan semakin banyaknya anggota dewan komisaris, pengawasan terhadap dewan direksi jauh lebih baik, masukan atau opsi yang akan didapat direksi akan jauh lebih banyak. Untuk itu masih diperlukan penelitian yang dapat membuktikan pengaruh ukuran dewan komisaris ini terhadap IPO underpricing. Oleh karena itu dikembangkan hipotesis yang kedua, yaitu :

\section{$\mathbf{H}_{2}$ : Komposisi dewan komisaris independen berpengaruh negatif terhadap IPO underpricing}

\section{Komite Audit}

Salah satu komponen dalam struktur corporate governance adalah komite audit. Menurut Rahmida (2012) dengan adanya komite audit pada perusahaan maka berpengaruh terhadap berkurangnya tingkat manajemen laba sehingga risiko yang akan ditanggung oleh investor akan berkurang sehingga kinerja perusahaan akan semakin membaik. Oleh karena itu dikembangkan hipotesis yang ketiga, yaitu :

\section{$\mathrm{H}_{3}$ : $\quad$ Komite audit berpengaruh negatif terhadap IPO underpricing}

\section{Kepemilikan Institusional}

Menurut Kurniasih dan Santoso (2008), adanya hubungan positif antara kepemilikan institusional dengan underpricing. Sedangkan Raja et al. (2014) menyimpulkan bahwa semakin besar kepemilikan institusional, maka akan semakin besar kekuatan suara dan dorongan dari institusi keuangan tersebut untuk mengawasi manajemen sehingga dapat membatasi tindakan manajemen laba dan diharapkan underpricing 
EKONOMI BISNIS DAN KEWIRAUSAHAAN

Vol. VIII, No. 1, Januari 2019

akan semakin kecil. Oleh karena itu, dikembangkan hipotesis keempat sebagai berikut.

\section{H4: Kepemilikan institusional berpengaruh negatif terhadap IPO underpricing}

\section{Kepemilikan Manajerial}

Chen dan Roger (2004) menyatakan adanya hubungan negatif antara proporsi saham yang dipegang oleh pemegang saham tunggal terbesar dengan underpricing. Sasongko (2014) menyatakan bahwa kepemilikan manjerial berpengaruh negatif terhadap underpricing. Oleh karena itu, dikembangkan hipotesis kelima sebagai berikut.

\section{H5: Kepemilikan manajerial berpengaruh negatif terhadap IPO underpricing}

\section{Dewan Direksi}

Menurut Kurniasih dan Santoso (2008) dan Darmadi dan Gunawan (2013), dewan direksi berpengaruh negatif dan signifikan terhadap tingkat underpricing. Oleh karena itu, dikembangkan hipotesis keenam sebagai berikut.

\section{H6: $\quad$ Dewan direksi berpengaruh negatif terhadap IPO underpricing}

\section{Reputasi Underwriter}

Menurut Indriani dan Marlia (2014), reputasi underwriter mempunyai pengaruh negatif terhadap IPO underpricing. Semakin bagus reputasi underwriter yang menjamin emisi saham maka semakin rendah tingkat underpricing. Dengan demikian, dapat dikembangkan hipotesis ketujuh, yaitu:

\section{$\mathrm{H}_{7}$ : Reputasi underwriter berpengaruh negatif terhadap IPO underpricing}

\section{TINJAUAN PUSTAKA}

\section{Initial Public Offering (IPO) Underpricing}

Menurut Ross et al (2015), pengertian Initial Public Offering (IPO) adalah kegiatan yang dilakukan perusahaan dalam rangka penjualan saham perdana. Gerianta (2008) mendefinisikan underpricing sebagai suatu keadaan, dimana harga saham pada saat penawaran perdana lebih rendah dibandingkan dengan ketika diperdagangkan di pasar sekunder (bursa efek). Underpricing dapat terjadi karena adanya informasi yang tidak sama antara pemilik perusahaan dengan investor dan dengan pihak underwriter (penjamin emisi saham).

Harga saham perusahaan pada saat IPO ditentukan berdasarkan kesepakatan antara perusahaan emiten dengan underwriter (Gunawan dan Halim, 2012). Underwriter merupakan pihak yang memiliki banyak informasi dan menggunakan ketidaktahuan pemilik perusahaan untuk memperkecil resiko. Jadi, pemilik perusahaan perlu mengetahui situasi pasar sebenarnya agar pada saat $I P O$, harga saham perusahaannya tidak mengalami underpricing.

Menurut Ediningsih (2007), fenomena underpricing yang terjadi pada hampir setiap pasar modal, akan menguntungkan investor karena mereka mendapatkan abnormal 
EKONOMI BISNIS DAN KEWIRAUSAHAAN

Vol. VIII, No. 1, Januari 2019

return tetapi tidak menguntungkan bagi perusahaan emiten karena tidak mendapatkan dana dalam jumlah yang optimal. Padahal salah satu tujuan perusahaan emiten menjual saham adalah meningkatkan atau menambah kas perusahaan.

\section{Reputasi Underwriter}

Salah satu faktor yang mempengaruhi IPO underpricing, yaitu reputasi underwriter. Menurut Samsul (2006), underwriter adalah pihak yang membuat kontrak dengan emiten untuk melakukan penawaran umum bagi kepentingan emiten dengan atau tanpa kewajiban membeli sisa efek yang tidak terjual. Underwriter merupakan pihak yang mengetahui atau memiliki banyak informasi pasar modal, sedangkan emiten merupakan pihak yang tidak mengetahui pasar modal. Dalam proses IPO, underwriter bertanggung jawab atas terjualnya saham.

Mengingat peranan penting underwriter dalam proses IPO, maka emiten secara selektif akan memilih underwriter yang prestisius agar dapat memperoleh mutu penjaminan terbaik (Widayani dan Yasa, 2013). Underwriter yang bereputasi baik berani menanggung risiko yang lebih besar dengan jalan menjamin saham yang ditawarkan dalam jumlah yang besar pula. Sebagai kompensasi atas penjaminannya, maka perusahaan emiten mengizinkan underwriter untuk menawarkan sahamnya pada harga yang lebih murah. Bagi investor, underwriter yang mampu menetapkan harga yang lebih murah akan dinilai sebagai underwriter yang bereputasi baik. Hal itu dikarenakan investor menilai bahwa underwriter yang bereputasi baik memiliki beban moral untuk menjamin harga saham ketika diperdagangkan di pasar sekunder tidak akan lebih rendah daripada harga saham yang ditawarkan di pasar perdana sehingga tidak akan merugikan investor

\section{Struktur Corporate Governance}

Corporate governance yang merupakan konsep yang didasarkan pada teori keagenan, diharapkan bisa berfungsi sebagai alat untuk memberikan keyakinan kepada para investor bahwa mereka akan menerima return atas dana yang telah mereka investasikan. Corporate governance merupakan suatu sistem yang mengatur dan mengendalikan perusahaan yang diharapkan dapat memberikan dan meningkatkan nilai perusahaan kepada para pemegang saham. Herawaty (2008), Struktur corporate governance, terdiri dari pemegang saham, komisaris, direksi, komite audit, sekretaris perusahaan, manajer dan karyawan, auditor eksternal, auditor internal, dan stakeholder lainnya (pemerintah, kreditur, dan lain-lain)

\section{Jumlah Anggota Dewan Komisaris}

Dalam Forum Corporate Governance Indonesia (FGCI, 2001), Indonesia menganut two tier board system dimana dalam struktur dewan terdapat pemisahan tugas antara fungsi pelaksana (dewan direksi) dan fungsi pengawasan (dewan komisaris). Jumlah anggota dewan komisaris berperan penting dalam mengurangi agency problem (masalah keagenan) antara manajer dan pemegang saham, selain itu jumlah anggota 
EKONOMI BISNIS DAN KEWIRAUSAHAAN

Vol. VIII, No. 1, Januari 2019

dewan komisaris akan sangat berpengaruh terhadap pelaksanaan kegiatan operasional perusahaan. Menurut Hermalin dan Weisbach (2003), board (dewan) dengan jumlah anggota yang lebih kecil akan lebih efektif dibandingkan dengan dewan dengan jumlah anggota yang lebih besar.

\section{Komisaris Independen}

Menurut Siallagan dan Machfoedz (2006), Board of directors (dewan komisaris) sebagai puncak dari sistem pengelolaan internal perusahaan, memiliki peranan terhadap aktivitas pengawasan. Fama dan Jensen (dalam Ujiyantho dan Pramuka, 2007) menyatakan bahwa non-executive director (komisaris independen) dapat bertindak sebagai penengah dalam perselisihan yang terjadi diantara para manajer internal dan mengawasi kebijakan manajemen serta memberikan nasihat kepada manajemen. Komisaris independen merupakan posisi terbaik untuk melaksanakan fungsi monitoring agar tercipta perusahaan yang good corporate governance.

\section{Komite Audit}

Komite audit memiliki peran yang penting dalam mewujudkan good corporate governance. Komite audit menjadi penghubung antara manajemen perusahaan dengan dewan komisaris maupun pihak ekstern lainnya. Komite audit juga berperan dalam mengawasi proses pelaporan keuangan perusahaan yang bertujuan untuk mewujudkan laporan keuangan yang disusun melalui proses pemeriksaan dengan integritas dan obyektivitas dari auditor

\section{Kepemilikan Institusional}

Kepemilikan institusional menggambarkan seberapa besar presentase kepemilikan perusahaan yang dimiliki oleh suatu institusi. Menurut Permanasari dan Kawedar (2010) kepemilikan institusional memiliki peranan yang sangat penting dalam meminimalisasi konflik keagenan yang terjadi antara manajer dan pemegang saham. Keberadaan investor institusional dianggap mampu menjadi mekanisme monitoring yang efektif dalam setiap keputusan yang diambil oleh manajer. Hal ini disebabkan investor institusional terlibat dalam pengambilan yang strategis sehingga tidak mudah percaya terhadap tindakan manipulasi laba.

Kepemilikan institusi menjadi hal yang menarik karena dalam suatu perusahaan terdiri atas berbagai kepemilikan dan pemilik sangat berkepentingan terhadap kinerja perusahaan. Investor institusional secara natural juga membentuk blockholders, yang memiliki kapabilitas potensial dalam menempatkan kinerja managemen setelah IPO.

\section{Kepemilikan Manajerial}

Pada agency theory, struktur kepemilikan yang dimiliki oleh pihak manajerial dapat dijadikan sebagai alat untuk mengurangi konflik keagenan antara manajer dengan pemegang saham. Kepemilikan manajerial merupakan suatu bentuk insentif yang diberikan perusahaan kepada manajemen dengan tujuan agar manajemen mampu 
EKONOMI BISNIS DAN KEWIRAUSAHAAN

Vol. VIII, No. 1, Januari 2019

meningkatkan kinerja perusahaan. Dengan adanya saham yang dimiliki manajer, hal ini membuat kedudukan manajer dan pemegang saham dapat disejajarkan.

Kepemilikan manajerial dinilai dapat mengurangi asimetri informasi dan mengurangi tingkat underpricing saat perusahaan melakukan IPO. Hal ini disebabkan karena apabila pihak manajerial memiliki saham di perusahaan, maka pihak manajemen pada saat melakukan IPO tentunya tidak menginginkan mengalami kerugian sehingga pihak manajemen akan berusaha secara maksimal dalam menetapkan harga penawaran perdana.

\section{Dewan Direksi}

Selain ukuran dan independensi dari dewan komisaris, saat ini prestige dan reputasi anggota dewan direksi memperoleh perhatian yang sedikit dalam konteks IPO. Menurut Certo (2003) Prestige dan reputasi dewan dapat diperoleh melalui akumulasi keterampilan, pengalaman, koneksi sosial, dan jaringan perusahaan. Certo (2003) mengembangkan proporsi dalam konteks pengaruh dari reputasi dewan terhadap proses pembuatan keputusan investor dan menyimpulkan bahwa konsep reputasi dewan merupakan subjek penting untuk lebih lanjut diteliti secara empiris.

\section{METODE PENELITIAN}

\section{A. Jenis Penelitian}

Penelitian ini merupakan suatu penelitian correlational study, mengacu Sugiyono (2013). Peneliti mencoba untuk melihat pengaruh faktor-faktor struktur corporate governance dan reputasi underwriter terhadap IPO underpricing di Indonesia. Penelitian ini merupakan penelitian ekspost facto (kausal komparatif) dengan menggunakan dimensi waktu cross sectional study, yaitu penelitian yang mengumpulkan data-data hanya dilakukan sekali dalam satu periode untuk menjawab suatu pertanyaan penelitian. Penulis hanya mengambil data sekali dalam penelitian ini yaitu periode waktu 1 Januari 2010 sampai 31 Desember 2016.

\section{B. Populasi Dan Sampel}

Populasi yang digunakan dalam penelitian ini adalah seluruh perusahaan yang melakukan Initial Public Offering (IPO) di Bursa Efek Indonesia (BEI) selama periode 2010-2016 yang ditelusuri dari IDX Fact Book. Penelitian ini menggunakan sampel yang diambil dengan cara non probability sampling mengacu Sugiyono (2013).

\section{Teknik Pengampilan Sampel}

Teknik pengambilan sampel pada penelitian ini adalah purposive sampling, dengan kriteria sebagai berikut : 
EKONOMI BISNIS DAN KEWIRAUSAHAAN

Vol. VIII, No. 1, Januari 2019

1. Sampel merupakan perusahaan yang listing di BEI periode 1 Januari 2010 sampai 31 Desember 2016 dan melakukan kegiatan Initial Public Offering (IPO).

2. Perusahaan memiliki laporan keuangan yang mencantumkan data-data dewan komisaris, komite audit, kepemilikan institusional, kepemilikan manajerial, dewan direksi dan reputasi underwriter.

3. Perusahaan tersebut mengalami underpricing pada saat Initial Public Offering (IPO)

dari syarat-syarat diatas didapatkan hasil seperti pada tabel 1, sebagai berikut :

Tabel 1. Seleksi Pemilihan Sampel

\begin{tabular}{llc}
\hline \multicolumn{1}{c}{ Keterangan } & Jumlah \\
\hline 1. Perusahaan yang melakukan IPO Periode 1 & 159 \\
& Januari 2010 sampai 31 Desember 2016 & \\
2. Perusahaan yang harga saham perdananya tidak & \\
& mengalami underpricing & $131)$ \\
3. Perusahaan yang mengalami underpricing & 128 \\
4. Perusahaan dengan data outlier & $(11)$ \\
5. Perusahaan yang terpilih sebagai sampel & 117 \\
\hline
\end{tabular}

\section{Sumber Data Dan Metode Pengumpulan Data}

Penelitian ini menggunakan data sekunder, yang terdiri dari :

1. Data Perusahaan yang melakukan IPO pada periode tahun 2010-2016. Data ini dapat diperoleh dari prospektus, IDX Fact Book, IDX Statistic dan Indonesian Capital Market Directory (ICMD).

2. Data harga pembukaan dan penutupan saham perdana (IPO), struktur corporate governance dan underwriter diperoleh dari Fact Book berbagai edisi, www.e-bursa.com dan www.duniainvestasi.com

3. Data keuangan diperoleh dari Indonesia Capital Market Directory (ICMD) berbagai edisi, prospektus, $\underline{w w w . e-b u r s a . c o m}$ dan $\underline{w w w . d u n i a i n v e s t a s i . c o m}$

\section{E. Definisi Operasional Dan Pengukuran Variabel}

\section{Variabel Dependen}

Variabel dependen yang digunakan dalam penelitian ini adalah underpricing. Underpricing merupakan selisih positif antara harga penutupan saham di pasar sekunder dengan harga saham pada penawaran perdana. Selisih harga ini dikenal sebagai initial return (IR). Initial Return dihitung berdasarkan selisih antara harga saham pada hari pertama penutupan (closing price) di pasar sekunder dibagi dengan harga penawaran saham perdana (offering Price) dikali 100. Secara sistematis dapat dirumuskan sebagai berikut : 
EKONOMI BISNIS DAN KEWIRAUSAHAAN

Vol. VIII, No. 1, Januari 2019

$$
\mathrm{IR}=\frac{(\mathrm{Pt} 1-\mathrm{Pt} 0) \times 100}{\mathrm{Pt} 0}
$$

Keterangan

IR = Initial return (return awal)

$\mathrm{P}_{\mathrm{t} 0}=$ harga penawaran perdana

$\mathrm{P}_{\mathrm{t} 1}=$ harga penutupan (Closing Price $)$ pada hari pertama perusahaan melakukan IPO

\section{Variabel Independen}

a. Ukuran Dewan Komisaris

Ukuran Dewan Komisaris yaitu jumlah seluruh dewan komisaris yang ada dalam suatu perusahaan. Variabel dewan komisaris ini dilambangkan dengan DE_KOM. Penelitian ini mengukur jumlah anggota dewan berdasarkan jumlah anggota dewan komisaris dalam perusahaan saat melakukan IPO.

b. Komposisi Dewan Komisaris Independen

Pada penelitian ini, komposisi dewan komisaris independen dilambangkan dengan KOM_IND. Variabel tersebut diukur dengan presentase dari rasio antara jumlah anggota dewan degan total anggota dewan komisaris perusahaan mengacu Darmadi dan Gunawan (2013). Secara sistematis dapat dirumuskan sebagai berikut :

\section{KOM_IND = Jumlah Komisaris Independen $\times 100 \%$ \\ Jumlah Dewan Komisaris}

\section{c. Komite Audit}

Variabel komite audit diukur berdasarkan ada tidaknya komite audit dalam perusahaan. Dalam penelitian ini, komite audit dilambangakan dengan KOM_AUD. Variabel komite audit menggunakan variabel dummy. Apabila perusahaan memiliki komite audit akan diberi nilai 1 dan apabila perusahaan tidak memiliki komite audit maka akan diberi nilai 0 mengacu Rahmida (2012).

\section{d. Kepemilikan Institusional}

Variabel kepemilikan institusional ini diukur berdasarkan persentase dari rasio antara total saham beredar dengan jumlah kepemilikan saham oleh institusi mengacu Darmadi dan Gunawan (2013). Variabel kepemilikan institusi dinyatakan dengan lambang KI. Secara sistematis dapat dirumuskan sebagai berikut :

$\mathrm{KI}=\underline{\text { Jumlah saham yang dimiliki institusi (dalam lembar) }} \times 100 \%$

Total saham beredar (dalam lembar)

e. Kepemilikan Manajerial 
EKONOMI BISNIS DAN KEWIRAUSAHAAN

Vol. VIII, No. 1, Januari 2019

Dalam penelitian ini, kepemilikan manjerial dilambangkan dengan KEP_MAN. kepemilikan saham oleh manajer merupakan variabel dummy. Angka 1 jika manajer memiliki saham pada perusahaan yang dipimpinnya dan angka 0 jika manajer tidak memiliki saham pada perusahaan yang dipimpinnya.

\section{f. Dewan Direksi}

Ukuran Dewan Direksi yaitu jumlah seluruh anggota dewan direksi yang ada dalam suatu perusahaan. Variabel dewan direksi ini dilambangkan dengan DIREK. Penelitian ini mengukur jumlah anggota dewan direksi berdasarkan jumlah anggota dewan direksi dalam perusahaan saat melakukan IPO.

\section{g. Reputasi Underwriter}

Pengukuran reputasi underwriter ini menggunakan variabel dummy, $1=$ jika perusahaan menggunakan jasa underwriter yang termasuk top 10 dalam $20^{\text {th }}$ Most Active Brokerage House Monthly in Total Trading Frequency selama periode penelitian dan $0=$ jika perusahaan menggunakan jasa underwriter di luar top 10 underwriter mengacu Yolana dan Martani (2005). Variabel reputasi underwriter dilambangakan dengan REP_UNDR

\section{F. Metode Analisis}

1. Uji Asumsi Klasik

Penelitian ini menggunakan uji normalitas, uji multikolinearitas, uji heteroskedastisitas dan uji autokorelasi mengacu Sugiyono (2013).

\section{Analisis Regresi Berganda}

Untuk mengukur hubungan antara variabel dependen dan variabel independen dalam penelitian ini digunakan analisis regresi linier berganda. Untuk menguji hipotesis digunakan model sebagai berikut :

$$
\mathrm{IR}=\beta_{0}-\beta_{1} \mathrm{KOM} \_ \text {IND }-\beta_{2} \mathrm{KOM} \_\mathrm{AUD}-\beta_{3} \mathrm{DIREK}-\beta_{4} \mathrm{REP} \_U N D+\mathrm{e}
$$

Keterangan :

IR

KOM_IND

KOM_AUD

DIREK

REP_UND

$\beta_{0}$

$\beta_{1}-\beta_{4}$

e
= Initial return (IPO Underpricing)

$=$ Komisaris Independen

$=$ Komite Audit

$=$ Jumlah Dewan Direksi

$=$ Reputasi underwriter

$=$ konstanta

$=$ Koefisien regresi

$=$ Residual/kesalahan regresi 
EKONOMI BISNIS DAN KEWIRAUSAHAAN

Vol. VIII, No. 1, Januari 2019

3). Uji Hipotesa

Untuk menguji hipotesis pada penelitian ini digunakan uji statistik $\mathrm{F}$, uji statistik $\mathrm{t}$ dan pengujian koefisien determinasi (uji $\mathrm{R}^{2}$ ) mengacu Sugiyono (2013).

\section{Hasil}

Berdasarkan hasil pengolahan data dengan program SPSS for Windows Versi 21, diperoleh hasil yang tercantum dalam tabel 2 sebagai berikut :

Tabel 2. Hasil Perhitungan Regresi Linier Berganda

\begin{tabular}{llcccc}
\hline No. & \multicolumn{1}{c}{$\begin{array}{c}\text { Variabel } \\
\text { Independen }\end{array}$} & Koefisien Regresi & $\begin{array}{c}\text { Standar Error } \\
\text { Of Estimates }\end{array}$ & thitung & Sig. T \\
\hline 1. & KOM_IND & 7,030 & 10,916 & 0,644 & 0,521 \\
2. & KOM_AUD & 2,492 & 4,589 & 0,543 & 0,588 \\
3. DIREK & $-3,920$ & 1,340 & $-2,926$ & 0,004 \\
4. $\quad$ REP_UND & $-9,312$ & 4,489 & $-2,074$ & 0,040 \\
\hline Dependen Variabel & & $:$ Underpricing & & \\
Konstanta & & $: 41,054$ & \\
Standard error of estimates & & $: 6,324$ & \\
Adjusted $R$ Square & & $: 0,127$ & \\
F Hitung & & $: 5,208$ & \\
Sig. F & & $: 0,001$ & \\
\hline
\end{tabular}

Sumber : Data sekunder yang diolah

Dari Tabel 2. di atas, dapat dibuat model persamaan regresi sebagai berikut :

$\mathrm{IR}=$ 41,054 + 7,030 KOM_IND - 2,492 KOM_AUD - 3,920 DIREK - 9,312

REP_UND + e

\section{Pembahasan}

a. Komposisi Dewan Komisaris Independen

Hasil penelitian ini menunjukkan komposisi dewan komisaris independen berpengaruh positif $(7,030)$ dan tidak signifikan $(p>0,05)$ terhadap IPO underpricing. Semakin besar komposisi dewan komisaris independen akan menambah tingkat IPO underpricing. Dalam penelitian ini komposisi dewan komisaris independen tidak mempunyai pengaruh terhadap IPO underpricing dimungkinkan karena dewan komisaris independen belum dianggap sebagai tolok ukur kualitas perusahaan. Dewan komisaris independen dinilai belum efektif menjalankan tugas monitoring dan mengevaluasi kinerja manajemen. 
b. Komite Audit

Hasil penelitian ini menunjukkan komite audit berpengaruh positif $(2,492)$ dan tidak signifikan $(p>0,05)$ terhadap IPO underpricing. Dalam penelitian ini adanya komite audit akan menambah tingkat IPO underpricing. Komite audit belum dapat dijadikan sinyal bagi perusahaan yang melakukan IPO karena peran komite audit dirasa belum maksimal di dalam perusahaan. Komite audit belum menjalankan fungsi pengawasan dengan baik. Perusahaan belum menyadari akan pentingnya keberadaan komite audit dalam perusahaan.

\section{c. Dewan Direksi}

Dalam penelitian ini dewan direksi berpengaruh negatif $(-3,920)$ dan signifikan $(p<0,05)$ terhadap IPO underpricing. Semakin banyak jumlah anggota dewan direksi akan mengurangi tingkat IPO underpricing. Hal ini dikarenakan dewan direksi mempunyai peran yang sangat vital di perusahaan. Dewan direksi bertanggung jawab mengelola kegiatan perusahaan sehari-hari, mengarahkan perusahaan untuk mencapai sasaran, tujuan dan aktivitas usaha yang telah direncanakan. Menurut investor, semakin banyak jumlah anggota dewan direksi sasaran perusahaan semakin mudah dicapai sehingga mampu meningkatkan keuntungan perusahaan. Hasil penelitian ini mendukung penelitian Kurniasih dan Santoso (2008) juga Darmadi dan Gunawan (2013) yang menyatakan dewan direksi berpengaruh negatif dan signifikan terhadap tingkat underpricing.

\section{d. Reputasi Underwriter}

Hasil penelitian ini menunjukkan bahwa reputasi underwriter berpengaruh negatif (9,312) dan signifikan $(\mathrm{p}<0,05)$ terhadap IPO underpricing. Semakin tinggi reputasi underwriter akan mengurangi tingkat underpricing saham. Underwriter yang memiliki reputasi tinggi lebih berani menjamin emisi saham dalam jumlah besar, sehingga harga saham pada saat IPO bisa diperkecil. Bagi perusahaan, tingkat underpricing saham yang rendah lebih menguntungkan karena akan mendapatkan dana dari investor secara maksimal. Hasil penelitian ini mendukung penelitian Indriani dan Marlia (2014) yang menyatakan reputasi underwriter mempunyai pengaruh negatif terhadap IPO underpricing.

\section{KESIMPULAN}

Dari hasil pengujian yang dilakukan terhadap 117 perusahaan yang melakukan IPO di Bursa Efek Indonesia tahun 2010-2016 diperoleh hasil bahwa :

1) Reputasi underwriter dan struktur corporate governance secara simultan berpengaruh terhadap IPO underpricing.

2) Struktur corporate governance yang mempunyai pengaruh negatif dan signifikan terhadap IPO underpricing di Indonesia adalah dewan direksi

3) Komposisi dewan komisaris independen dan komite audit tidak berpengaruh signifikan terhadap IPO underpricing. 
EKONOMI BISNIS DAN KEWIRAUSAHAAN

Vol. VIII, No. 1, Januari 2019

4) Reputasi underwriter secara parsial berpengaruh negatif dan signifikan terhadap IPO underpricing.

\section{DAFTAR PUSTAKA}

Certo, S. T. (2003). Influencing initial public offering investors with prestige: Signaling with board structures. Academy of Management Review, 28(3), $432-446$.

Chen, J. and Strange, Roger. (2004). The Effect of Ownership Structure on the Underpricing of Initial Public Offerings : Evidence from Chinese Stock Market, working paper, King's College London, London, April

Darmadi, Salim dan Randy Gunawan. (2013). Underpricing, Board Structure and Ownership : An Empirical Examination of Indonesian IPO Firms. Manajerial Finance. 39(2), 101-200

Ediningsih, Isworo Sri. (2007). Fenomena Underpricing pada Penawaran Umum Perdana di Indonesia. Jurnal Ekonomi dan Bisnis, 8(1), 99-105

Gunawan, Barbara dan Mazda Halim. (2012). Pengaruh Ownership Retention, Reputasi Auditor, Laba Perusahaan, dan Underpricing Terhadap Nilai Perusahaan Dengan Kepemilikan Manajerial dan Institusional Sebagai Variabel Pemoderasi. Jurnal Akuntansi \& Investasi, 13(2), 99-115

Herawaty, Vinola. (2008). Peranan Praktek Corporate Governance Sebagai Moderating Variabel dari Pengaruh Earning Manajemen Terhadap Nilai Perusahaan. Jurnal Akuntansi dan Keuangan, 10(2), 97-108

Hermalin, B. E., and Weisbach, M. S. (2003). Board of Directors as Endogenously Determined Institution : a Survey of the Economic Literature. Federal Reserve Bank of New York Economic Policy Review, 9(1), 1-20.

Hidayat, Arif Wahyu dan Retno Kusumastuti. (2014). The Influence of Corporate Governance Structure towards Underpricing. International Journal of Administrative Science \& Organizations, 21(2), 90-96

Indriani, Susi dan Sri Marlia. (2014). The Evidence of IPO Underpricing in Indonesia 2009-2013. Review of Integrative Business \& Economics Research, 4(1), 299-316

IDX Statistics 2010. Indonesian Stock Exchange

IDX Statistics 2011. Indonesian Stock Exchange

IDX Statistics 2012. Indonesian Stock Exchange

IDX Statistics 2013. Indonesian Stock Exchange

IDX Statistics 2014. Indonesian Stock Exchange

IDX Statistics 2015. Indonesian Stock Exchange

IDX Statistics 2016. Indonesian Stock Exchange 
EKONOMI BISNIS DAN KEWIRAUSAHAAN

Vol. VIII, No. 1, Januari 2019

Johnston, J. and Madura, J. (2009). The pricing of IPOs post-Sarbanes-Oxley. The Financial Revew, 44(2), 291-310.

Kurniasih, Lulus dan Arif. L. Santoso. (2008). Bukti Empiris Fenomena Underpricing dan Pengaruh Mekanisme Corporate Governance. Jurnal Ekonomi dan Kewirausahaan, 8(1), 1 - 15

Lin, C. P. and Chuang, C. M. (2011). Principal-pricipal Conflicts and IPO Pricing in an Emerging Economy. Corporate Governance: An International Review, 19(6), 585-600.

Noviawan, Ridho Arief dan Aditya Septiani. (2013). Pengaruh Mekanisme Corporate Governance Dan Struktur Kepemilikan Terhadap Kinerja Keuangan. Diponegoro Journal Of Accounting, 2(3), 1-10

Nuswandari, Cahyani. (2009). Pengaruh Corporate Governance Perception Index Terhadap Kinerja Perusahaan Pada Perusahaan Yang Terdaftar Di Bursa Efek Jakarta. Jurnal Bisnis dan Ekonomi (JBE), 16(2), 70 - 84

Rahmida, Amanda Ratna. (2012). Pengaruh Karakteristik Dewan Komisaris, Keberadaan Komite Audit, Kualitas Auditor Eksternal dan Monitoring Bank Terhadap Tingkat Underpricing Saat Initial Public Offering. Jakarta : Universitas Indonesia, Tesis, Hal. 1-11

Ross, Stephen A; Westerfield, Randolph W; Jorda, Bradford D; Lim, Joseph dan Ruth Tan. (2015). Pengantar Keuangan Perusahaan, Edisi Global Asia Buku 1. Jakarta : Salemba Empat

Samsul, Mohamad. (2006). Pasar Modal dan Manajemen Portofolio. Surabaya : Erlangga.

Sasongko, Bangkit dan Agung Juliarto. (2014). Analisis Pengaruh Tata Kelola Perusahaan Terhadap Tingkat Underpricing Penawaran Umum Perdana Saham (Studi Empiris Terhadap Perusahaan Non Finansial Di Bursa Efek Indonesia). Diponegoro Journal of Accounting, 3(2), 1-10

Siallagan, Hamonagan \& Mas'ud Machfoedz. (2006). Mekanisme Corporate Governance, Kualitas Laba dan Nilai Perusahaan. Simposium Nasional Akuntansi IX, Padang, 23-26 Agustus.

Sugiyono, Prof. Dr. (2013). Metode Penelitian Kuantitatif Kualitatif dan R\&D. Bandung : CV Alfabeta

Ujiyantho, Muh. Arief dan Bambang Agus Pramuka. (2007). Mekanisme Corporate Governance, Manajemen Laba dan Kinerja Keuangan (Studi pada Perusahaan Go Publik Sektor Manufaktur). Simposium Nasional Akuntansi X, Unhas Makasar, 26-28 Juli 2007. 
EKONOMI BISNIS DAN KEWIRAUSAHAAN

Vol. VIII, No. 1, Januari 2019

Widayani, Ni Luh Ulansari Manikan dan Gerianta Wirawan Yasa. (2013). Tingkat Underpricing dan Reputasi Underwriter. E-Jurnal Akuntansi Universitas Udayana, 4(1), 159-176

Yolana, C dan D. Martani. (2005). Variabel-variabel yang Mempengaruhi Fenomena Underpricing Pada Penawaran Saham Perdana di BEJ Tahun 1994 - 2001. Proceedings of the eight annual meeting of the Indonesian Accounting Association. Simposium Nasional Akuntansi VIII, Solo, Indonesia, 538-553.

http: //www.e-bursa.com

http ://www.duniainvestasi.com

http ://www.fcgi.or,.id

http://www.idx.co.id 